\title{
Development and Validation of a Stability-Indicating RP-HPLC Method for Determination of Darifenacin Hydrobromide in Bulk Drugs
}

\author{
Mohammed Nazeerunnisa1, Lakshmi Garikapati², Syama Sundar Bethanabhatla ${ }^{1,3^{*}}$ \\ ${ }^{1}$ Department of Chemistry, Acharya Nagarjuna University, Guntur, India \\ ${ }^{2}$ Centre for Pharmaceutical Sciences, Jawaharlal Nehru Technological University, Hyderabad, India \\ ${ }^{3}$ Yogi Vemana University, Kadapa, India \\ Email: " profbsyamsundar@yahoo.co.in
}

Received 10 October 2014; revised 27 November 2014; accepted 13 December 2014

Academic Editor: Sai Raghuveer Chava, KC Pharmaceuticals Inc., USA

Copyright @ 2014 by authors and Scientific Research Publishing Inc.

This work is licensed under the Creative Commons Attribution International License (CC BY).

http://creativecommons.org/licenses/by/4.0/

(c) (i) Open Access

\begin{abstract}
An isocratic stability-indicating reversed phase high performance liquid chromatographic method (RP-HPLC) was developed for determination of process related impurities and assay of darifenacin hydrobromide (DRF) in bulk drugs. DRF was subjected to various stress conditions such as hydrolysis (acid, base, and neutral), oxidation, photolysis and thermal degradation as per International Conference on Harmonization (ICH Q1A(R2) and Q1B) prescribed conditions to investigate the stability-indicating ability of the method. Significant degradation was observed during acidic hydrolysis and oxidative stress conditions. The chromatographic separation was accomplished on a Prodigy $\mathrm{C}_{8}$ column $(250 \times 4.6 \mathrm{~mm}, 5 \mu \mathrm{m})$ with mobile phase consisting of $0.05 \mathrm{M}$ ammonium acetate ( $\mathrm{pH}$ adjusted to 7.2 by using ammonia solution) and methanol (36\% acetonitrile) in 35:65 v/v ratio in an isocratic elution mode at a flow rate of $1.0 \mathrm{~mL} / \mathrm{min}$ at $25^{\circ} \mathrm{C}$. Detection of analytes was carried out using photo diode array detector at a wavelength of $215 \mathrm{~nm}$. The developed LC method was validated with respect to accuracy, linearity, precision, limits of detection and quantitation and robustness as per ICH guidelines.
\end{abstract}

\section{Keywords}

Darifenacin Hydrobromide, Stability-Indicating, Degradation, Validation, RP-HPLC

\footnotetext{
${ }^{*}$ Corresponding author.
}

How to cite this paper: Nazeerunnisa, M., Garikapati, L. and Bethanabhatla, S.S. (2014) Development and Validation of a Stability-Indicating RP-HPLC Method for Determination of Darifenacin Hydrobromide in Bulk Drugs. American Journal of Analytical Chemistry, 5, 1239-1248. http://dx.doi.org/10.4236/ajac.2014.517130 


\section{Introduction}

Darifenacin hydrobromide (DRF), a novel antimuscarinic agent, chemically known as (S)-2-[1-[2-(2,3-dihydrobenzofuran-5-yl)ethyl] pyrrolidin-3-yl]-2,2-diphenyl-acetamide hydrobromide, is a medication used to treat overactive bladder with symptoms of urge urinary incontinence, urgency, and frequency. It works by blocking the $\mathrm{M}_{3}$ muscarinic acetylcholine receptor selectively, which is primarily responsible for bladder contractions, thereby decreases the urgency to urinate [1] [2].

An extensive survey of literature revealed that few chromatographic methods have been published for the quantification of DRF and related substances. S. Thomas et al. reported a selective stability-indicating HPLC method for DRF in the presence of process related impurities and stress degradation products and characterization of degradation products by LC-MS studies [3]. Despite of the separation of several related substances and DRF, the method has limitations of using ion-pairing mobile phase additive, very high run time, and poor peak shape of DRF. M. V. Murthy et al. reported a stability-indicating UPLC method [4]. A stability-indicating LC method with chemometric evaluation of DRF was also reported [5]. A chiral stability-indicating assay method for the determination of DRF and its enantiomer and a chiral LC Method for enantiomeric purity determination of DRF in bulk drugs and extended release tablets were also reported [6] [7]. K. Srinivas et al. reported an impurity profile method for batch analysis of DRF [8]. In addition, B. Kaye et al. reported a solid phase extraction of DRF in human plasma [9]. To the best of our knowledge, no rapid stability-indicating HPLC method for the quantitative determination of DRF in drug substance in presence of more susceptible process related impurities in bulk drugs was reported.

The main target of the present research work was to develop a selective, rapid and stability-indicating HPLC method for the determination of DRF and its related substances. The developed method was validated with respect to specificity, limits of detection (LOD), limits of quantitation (LOQ), linearity, precision, accuracy, solution and mobile phase stabilities, and robustness as per International Conference on Harmonization (ICH Q2R1) guidelines [10]. Forced degradation studies were performed on the DRF drug substance to establish the stabilityindicating nature of the method in accordance with established ICH guidelines [11].

\section{Experimental}

\subsection{Reagents and Chemicals}

HPLC grade acetonitrile and methanol and AR grade ammonium acetate and ammonia solutions were purchased from S.D. Fine chemicals Pvt. Ltd., Mumbai, India. High purity water was obtained by using Millipore Milli-Q water purification system (Millipore synergy, France). Samples of DRF and its three process related impurities (Imp-1: 2,2-Diphenyl-2-[(3S)-pyrrolidin-3-yl]acetamide tartarate, Imp-2: 5-(2-bromoethyl)-2,3-dihydrobenzofuran, Imp-3: N-(2-(2,3-dihydrobenzofuran-5-yl)ethyl)-2-(1-(2-(2,3-dihydrobenzofuran-5-yl)ethyl)pyrrolidin-3yl)-2,2-diphenyl acetamide) were received from a local industry, Hyderabad, India. Structures of DRF and impurities are shown in Figure 1. Among three impurities Imp-1 and Imp-2 are substrates and Imp-3 is a dimeric by-product. All required sample solutions, and solvents were filtered through $0.45 \mu \mathrm{m}$ PTFE filter papers.

\subsection{Equipment}

The HPLC system used for method development, forced degradation studies and method validation consisted of a quaternary UFLC LC-20AD liquid chromatograph pump module, a DGU-20A $\mathrm{A}_{5}$ degasser, a SIL-20AC auto sampler, a CTO-20AC column oven compartment, a SPD-M20A photo diode array detector, and CBM-20A communications bus module (All from Shimadzu, Kyoto, Japan). The chromatographic and the integrated data were recorded using HP (Hewlett Packard, India) computer system using Lab Solutions data acquisition software (Shimadzu, Kyoto, Japan).

\subsection{Chromatographic Conditions}

The chromatographic column used was Prodigy $\mathrm{C}_{8}$ column $\left(250 \times 4.6 \mathrm{~mm}, 5 \mu \mathrm{m}\right.$ particle size, $\left.150 \mathrm{~A}^{\circ}\right)$ of Phenomenex make. The batch and serial numbers of the column are 5182-22 and 585196-1, respectively. All the chromatograms given in this paper are of this column. Another Prodigy $\mathrm{C}_{8}$ column of same dimensions but with 


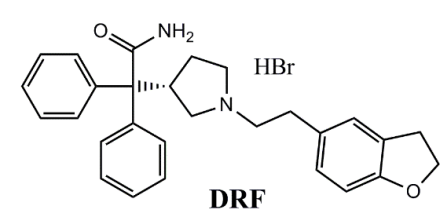

DRF

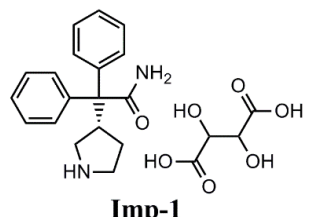

Imp-1
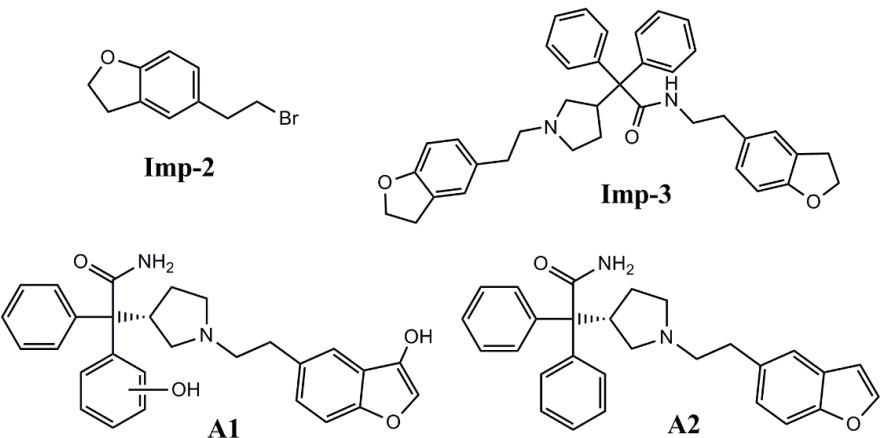

A1

A2
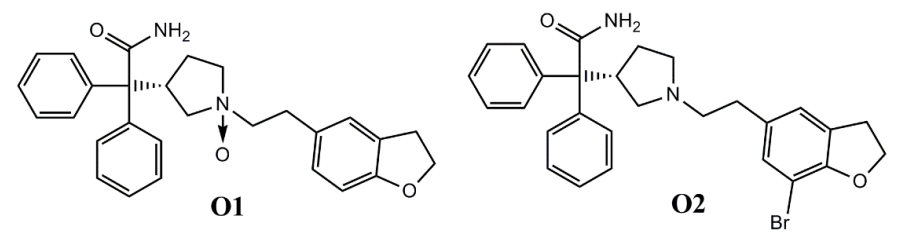

Figure 1. Chemical structures of DRF, impurities (Imp-1, Imp-2, and Imp-3), and degradation of products (A1, A2, O1, and O2).

different batch (5234-033) and serial number (652229-1) is used for intermediate precision study. The mobile phase used consists of (solvent $\mathrm{A}$ ) $0.05 \mathrm{M}$ ammonium acetate $\mathrm{pH}$ adjusted to 7.2 by using ammonia solution, and (solvent B) methanol and acetonitrile in 64:36 v/v ratio. The separation was achieved in an isocratic elution mode at 50:50 v/v ratio of solvent $A$ and solvent $B$ at a flow rate of $1.0 \mathrm{~mL} / \mathrm{min}$ at a column temperature of $25^{\circ} \mathrm{C}$. The chromatograms were monitored at a wavelength of $215 \mathrm{~nm}$. The injection volume was $10 \mu \mathrm{L}$. A mixture of methanol and water $(1: 1 \mathrm{v} / \mathrm{v})$ was used as diluent.

\subsection{Preparation of Standard Solutions and Sample Solutions}

Stock solutions of DRF (2.0 mg/mL) and all impurities $(0.5 \mathrm{mg} / \mathrm{mL}$ each) were prepared by dissolving in minimum amount of methanol and made up to volume with diluent. Working solutions of DRF spiked and unspiked with impurities were prepared from the stock solution for the determinations of related substances and assay, respectively.

\subsection{Forced Degradation Studies and Specificity}

Specificity is the ability of the method to measure the analyte (DRF) response unequivocally in the presence of its possible impurities. The specificity of the developed HPLC method for DRF was determined in the presence of its process related impurities (Imp-1 to Imp-3 at 0.15\%) and degradation products formed under stress. Forced degradation studies of drug can help to identify the likely degradation products, also they in turn can help to establish the degradation pathways and the intrinsic stability of the molecule. In order to develop a specific stability-indicating method, forced degradation studies were carried out on DRF active pharmaceutical ingredient powder. DRF was subjected to various stress conditions and generated samples were injected into HPLC at regular intervals and the final stress conditions were established in such a way to get significant degradation. Applied stress conditions are acidic hydrolysis $\left(0.5 \mathrm{~N} \mathrm{HCl}\right.$, reflux at $70^{\circ} \mathrm{C}$ for $\left.18 \mathrm{~h}\right)$, basic hydrolysis $(1 \mathrm{~N} \mathrm{NaOH}$, reflux at $70^{\circ} \mathrm{C}$ for $24 \mathrm{~h}$ ), neutral hydrolysis (reflux at $70^{\circ} \mathrm{C}$ for $24 \mathrm{~h}$ ), oxidation ( $3 \%$ hydrogen peroxide, in the dark at room temperature for 10 days), thermal (DRF powder in a petri dish was placed in a temperature controlled dry air oven (Cintex Industrial Corporation, Mumbai, India) maintained at $60^{\circ} \mathrm{C}$ for 10 days), and Photo 
(DRF powder and solution were kept under fluorescent and UV light in a photostability chamber (Sanyo, UK) for a period of 1.2 million Lux hours and $200 \mathrm{Wh} / \mathrm{m}^{2}$, respectively). Samples of acid and base hydrolyses were neutralized, and all the degradation samples were diluted five times for assay determination. Assays were performed by comparison with standard and the mass balances (\% assay $+\%$ impurities + $\%$ degradation products) were calculated for stressed samples. The three degradation samples of each stress were injected into an LC-PDA system to check the purity and homogeneity of the drug peak.

\subsection{Method Validation}

The validation of the developed HPLC method was carried out for the determination of related substances (Imp1 to Imp-3) and assay of DRF as per ICH guidelines to demonstrate that the method is appropriate for its intended use.

\subsubsection{System Suitability}

The system suitability tests were conducted and evaluated by injecting six replicates of $800 \mu \mathrm{g} / \mathrm{mL}$ (spiked with $0.15 \%$ of all impurities), and $100 \mu \mathrm{g} / \mathrm{mL}$ of DRF solutions for related substance and assay methods, respectively.

\subsubsection{Precision}

The system precision was evaluated by analyzing six replicates of standard solution for both assay (DRF 100 $\mu \mathrm{g} / \mathrm{mL}$ ) and related substances (DRF (800 $\mu \mathrm{g} / \mathrm{mL}$ ) spiked with $0.15 \%$ each impurity) individually. The method precisions for assay and related substances were evaluated by injecting six individual test preparations of DRF $(100 \mu \mathrm{g} / \mathrm{mL})$, and DRF (800 $\mu \mathrm{g} / \mathrm{mL})$ spiked with $0.15 \%$ each impurity, respectively. The intermediate precisions were evaluated on three different days by a different analyst using different batch column of same manufacturer and instrument located within the same laboratory. Precision at LOQ levels was also determined by injecting six individual preparations of mixture of all impurities spiked to DRF $(800 \mu \mathrm{g} / \mathrm{mL})$ at their LOQ level. The \%RSDs of the areas of each impurity and assay of DRF were calculated for precision studies.

\subsubsection{Limit of Detection (LOD) and Limit of Quantification (LOQ)}

To establish the minimum concentration at which the analyte was reliably detected (LOD) and quantified (LOQ), the signal-to-noise ratios were determined. The LOD and LOQ for Imp-1, Imp-2, Imp-3 and DRF were estimated at a signal-to-noise ratio of 3:1 and 10:1, respectively, by injecting a series of dilute solutions with known concentrations.

\subsubsection{Linearity}

Linearity of the related substance method was established by analyzing series of dilute solutions at six different concentration levels ranging from LOQ to $250 \%$ to the specification level of impurities (i.e., LOQ, 0.6, 1.2, 1.8, 2.4 , and $3.0 \mu \mathrm{g} / \mathrm{mL})$ spiked into DRF drug substance $(800 \mu \mathrm{g} / \mathrm{mL})$. The calibration curves were drawn by plotting the peak areas of impurities against their corresponding concentrations. Similarly, assay method linearity was established by injecting DRF at five different concentration levels ranging from $50 \%$ to $150 \%$ (i.e., 50,75 , $100,125$, and $150 \mu \mathrm{g} / \mathrm{mL})$ to DRF concentration $100 \mu \mathrm{g} / \mathrm{mL}$. The correlation coefficients $\left(r^{2}\right)$, slopes and Y-intercepts of impurities and DRF were determined from their respective calibration plots.

\subsubsection{Accuracy}

Accuracy of the related substance method was evaluated by spiking known amounts of the impurities into the test sample, analyzing the same and calculating the percent recovered. For related substances, the recovery studies were performed in triplicate at three concentration levels $(50 \%, 100 \%$ and $150 \%)$ to specification level (0.15\%) of impurities (i.e., 0.6, 1.2, and $1.8 \mu \mathrm{g} / \mathrm{mL}$ ) with respect to DRF drug substance concentration 800 $\mu \mathrm{g} / \mathrm{mL}$. The accuracy of the DRF assay was evaluated in triplicate at the three concentration levels $50 \%, 100 \%$ and $150 \%$ (i.e., 50, 100 and $150 \mu \mathrm{g} / \mathrm{mL}$ ) to DRF concentration $100 \mu \mathrm{g} / \mathrm{mL}$, and the recovery was calculated for each concentration.

\subsubsection{Robustness}

Robustness study was carried out to check the influence of small variations in the optimized chromatographic 
conditions. The typical parameters investigated include flow rate $( \pm 10 \%$ to $1.0 \mathrm{~mL} / \mathrm{min})$, mobile phase $\mathrm{pH}( \pm 0.2$ to 7.2), and column temperature $\left( \pm 3^{\circ} \mathrm{C}\right.$ to $25^{\circ} \mathrm{C}$ ). System suitability parameters and changes in assay of DRF and recoveries of impurities were checked. In all the above deliberately altered experimental conditions, the mobile phase compositions were held constant.

\subsubsection{Solution Stability and Mobile Phase Stability}

The solution stability of DRF and its impurities was carried out by leaving unspiked and spiked sample solutions in a tightly capped volumetric flask at $2^{\circ} \mathrm{C}-8^{\circ} \mathrm{C}$ for $48 \mathrm{~h}$. Content of impurities and assay of DRF were determined at $8 \mathrm{~h}$ intervals. Mobile phase stability was assessed by comparative analysis of freshly prepared sample solutions and freshly prepared reference standard solution up to $48 \mathrm{~h}$.

\section{Results and Discussion}

\subsection{Optimization of Chromatographic Conditions}

The main objective of the development of a chromatographic method was to get the good separation of impurities and stress degradation products from DRF and each other. For method development DRF, DRF spiked with impurities, acid and oxidative stress generated samples were injected simultaneously. In the initial stages of method development with $\mathrm{C}_{18}$ stationary phase columns (Agilents' XDB and Extend) showed very quick elution of Imp-1 and DRF along with peak asymmetry with several mobile phase compositions consisting of acetate/ phosphate buffers and acetonitrile/methanol due to their high polarity. To increase the retention of DRF, moderately polar $\mathrm{C}_{8}$ stationary phase column was employed instead of nonpolar $\mathrm{C}_{18}$ column. Replacement of $\mathrm{C}_{18}$ with $\mathrm{C}_{8}$ resulted in good peak parameters with increased retentions of Imp- 1 and DRF compared to $\mathrm{C}_{18}$. As the pKa value of DRF $(\approx 9.2)$ is higher, buffers with higher $\mathrm{pH}$ were chosen initially with $\mathrm{C}_{8}$ stationary phase column. Disodium hydrogen orthophosphate $(0.02 \mathrm{M}$, pH adjusted to 7.0 with orthophosphoric acid) buffer with acetonitrile showed peak asymmetry (tailing $>2$ ), but with methanol good peak parameters for DRF were resulted. At lower concentrations of methanol, peak fronting and higher retention times of analytes were observed. As the methanol concentration increases to decrease the LC run time, improvement in peak symmetry (tailing factor 1.05) with good column efficiency (Plate count $>9000$ ) for DRF (assay peak) was observed, but showed co-elution of Imp-3 with DRF (spiked sample). Buffers with lower pH $(\approx 4.0)$ showed peak asymmetry. Trails with mono phosphate buffer $\left(\mathrm{KH}_{2} \mathrm{PO}_{4}\right)$ also resulted in same type of results.

Later, improved separation between analytes and difference in elution order was observed when phosphate buffer was replaced by ammonium acetate buffer. During method development with ammonium acetate buffer, several isocratic methods were employed and the effects of ionic strength of buffer, $\mathrm{pH}$ and organic modifier compositions on peak parameters were studied.

\subsubsection{Effect of Buffer Concentration}

The effect of concentration of ammonium acetate buffer on separation was studied by varying its concentration from 0.01 to $0.05 \mathrm{M}$ on Prodigy $\mathrm{C}_{8}$ column maintained at $25^{\circ} \mathrm{C}$. The change in the concentration of ammonium acetate had shown no much effect on the retention of the analytes, and on resolution. But peak tailing of DRF was improved form $>2$ to $<1.5$ with an improvement in theoretical plates number from $<2000$ to $>3000$ with an increase in concentration of ammonium acetate from 0.01 to $0.05 \mathrm{M}$. Sharp symmetrical peaks with good resolution were obtained with $0.05 \mathrm{M}$ ammonium acetate buffer. The desired symmetry and resolution were obtained with $0.05 \mathrm{M}$ of ammonium acetate; it was used for further optimization of other variables.

\subsubsection{Effect of Buffer $\mathrm{pH}$}

The effect of ammonium acetate buffer $\mathrm{pH}$ on peak parameters was studied from 4.0 to 7.5 (adjusted with acetic acid and ammonia solution). Buffer with $\mathrm{pH} 4.0$ was found to be not suitable as the poor retention of Imp-1, Imp-3, degradation products, and DRF resulted coelution. At $\mathrm{pH}$ 5.0, better resolutions were also not achieved and tailing was found more for DRF. As $\mathrm{pH}$ increases to 6.0, DRF, impurities and degradation products were separated from each other with better resolutions, but failed to get desirable tailing factors and theoretical plates. With an increase of $\mathrm{pH}$ to 7.5, better resolutions were obtained with an improvement in peak parameters. Finally, after several trials with buffers at different $\mathrm{pH}$, it could be seen that at $\mathrm{pH} 7.2$, all the peaks with good resolutions and desirable peak tailings and theoretical plates were obtained. 


\subsubsection{Effect of Organic Modifier}

Employment of different compositions of organic modifier using methanol and acetonitrile played key role in achieving optimized method. With methanol alone it was observed that, merging of DRF, degradation products, and Imp-3 at higher concentrations. Decrease of methanol percentage resulted in the enhanced retention of nonpolar analyte Imp-2 and increase in resolutions with increase in peak fronting of DRF. Similarly, at higher percentage of acetonitrile coelution of DRF with degradation products and Imp-3 was observed. Unlike methanol, lower concentrations of acetonitrile resulted good resolutions with peak tailing. From these results we had come to a conclusion that combination of methanol and acetonitrile may result in a method that can be capable of eluting all the analytes with good resolutions with improved peak parameters. The effect of acetonitrile concentration in methanol (total organic modifier concentration was set as 60) was studied on peak parameters of DRF, and found that increase in tailing factor and increase in theoretical plates with increase in the percentage of acetonitrile. But it was observed that increase of acetonitrile percentage causes the lowering of resolution between degradation products and Imp-3. In order to increase the resolution, total organic modifier concentration was decreased to 55 without changing the acetonitrile percentage in methanol, and found increased resolution between Imp-3 and degradation products with no change in tailing factor and an additional improvement in theoretical plates number of DRF. Finally, 36\% of acetonitrile was chosen as the optimized combination with methanol.

Finally, after several attempts, an optimized separation was accomplished on a Prodigy $\mathrm{C}_{8}(250 \times 4.6 \mathrm{~mm}, 5$ $\mu \mathrm{m})$ column in an isocratic elution mode with a mobile phase composed of $0.05 \mathrm{M}$ ammonium acetate $(\mathrm{pH}$ was adjusted to 7.2 with ammonia solution) and methanol with $36 \%$ acetonitrile in $45: 55$ (v/v) ratio at a flow rate of $1.0 \mathrm{~mL} / \mathrm{min}$ and at a column temperature of $25^{\circ} \mathrm{C}$. The injection volume was set as $10 \mu \mathrm{L}$. Chromatogram showing the separation of impurities from DRF under optimized conditions is shown in Figure 2, samples of three different batches.

\subsection{Specificity and Degradation Behavior of DRF}

The assay of DRF for three determinations was found to be $99.5 \%$ with \%RSD of 0.8 ; while in the presence of impurities $(0.15 \% \mathrm{w} / \mathrm{w})$ it was $99.2 \%$ with \%RSD of 0.5 . It suggests that the assay did not change in the presence of impurities. No considerable degradation of DRF was observed under neutral and basic hydrolytic, photolytic, and thermolytic stress conditions. Significant degradation of DRF drug substance was observed in acidic hydrolytic and oxidative stress conditions as shown in Figure 3. Peak purity test results obtained from PDA detector confirmed that the DRF peak was homogeneous and pure in all the analyzed stress samples. The mass balance of stressed samples was found in the range of $98.1 \%$ to $99.7 \%$. The forced degradation results are summarized in Table 1. From references 3 and 4, the predicted structures of degradation products formed under acidic (A1 and A2) and oxidative (O1 and O2) stress are shown in Figure 1. Respective retention and relative retention times of degradation products are $\mathrm{A} 1=8.35,0.854$; $\mathrm{A} 2=13.02,1.331 ; \mathrm{O} 1=6.80,0.695$; and $\mathrm{O} 2=$ $16.53,1.690$. Chromatogram of mixture of acidic and oxidative stress sample solution spiked with impurities showing good separation confirms the method specificity and selectivity (Figure 4).

\subsection{Method Validation}

\subsubsection{System Suitability}

System suitability data (Table 2) indicating that the system was suitable for use as the tailing factor for all the analytes was less than 1.2 and the resolution between any of the two adjacent eluting analytes was greater than 2.6. It also confirms the good selectivity of the method.

\subsubsection{Sensitivity}

The LOD and LOQ results of DRF and its three process related impurities estimated at a signal-to-noise ratio of 3:1 and 10:1 respectively were summarized in Table 2.

\subsubsection{Precision}

The \%RSD results of precision studies (system, method, intermediate and at LOQ) for both DRF assay and related substances methods were found in the range of $0.23-0.79$ and $0.32-4.82$, respectively confirming the high precision of the method. The results of precision studies were given in Table 2. 


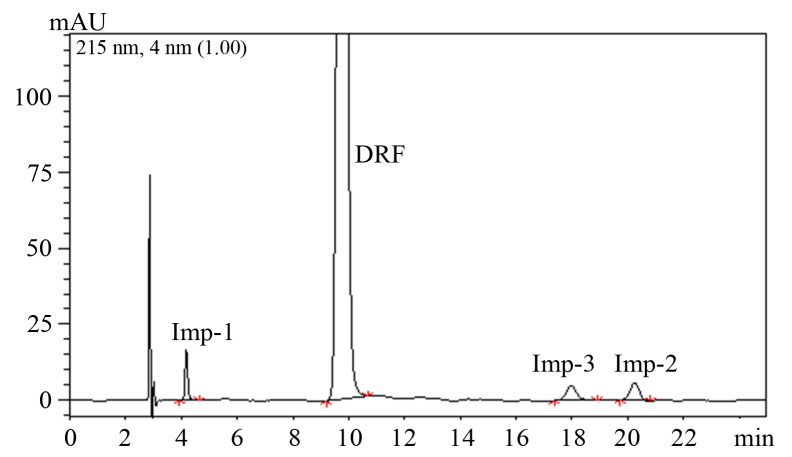

Figure 2. Chromatogram of DRF spiked with process related impurities.

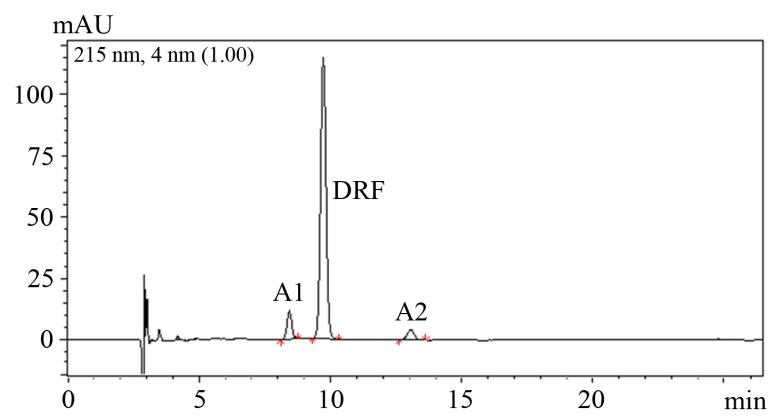

(a)

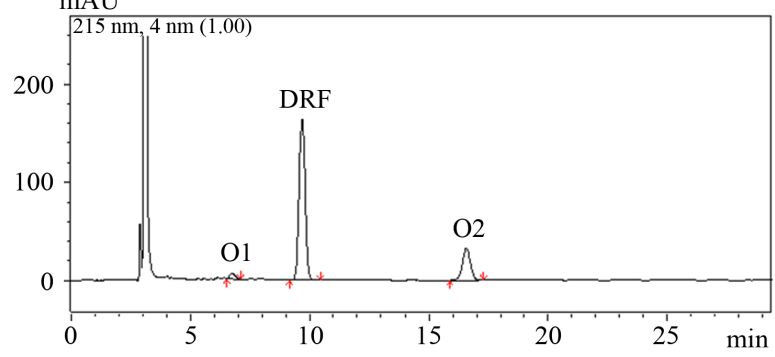

(b)

Figure 3. Typical chromatograms of DRF under stress (a) acidic hydrolysis, and (b) oxidation.

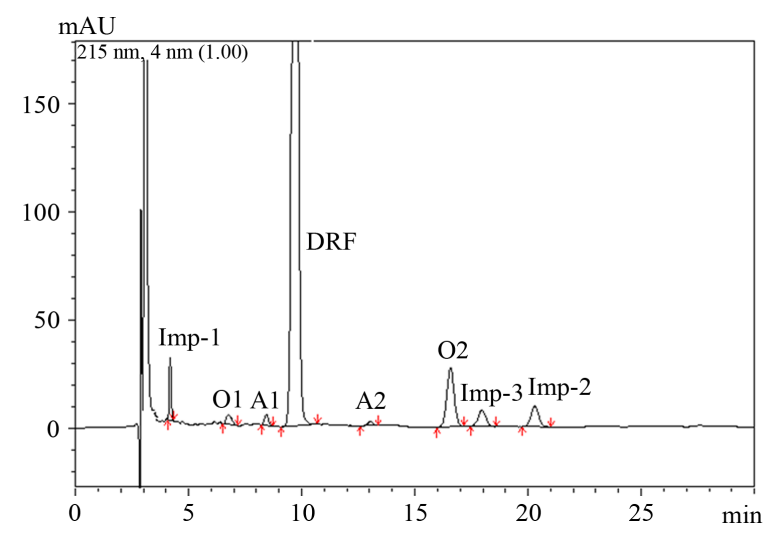

Figure 4. Chromatogram of mixture of acidic and oxidative stress sample spiked with impurities. 
Table 1. Summary of forced degradation studies.

\begin{tabular}{|c|c|c|c|c|}
\hline Stress condition & Time & $\begin{array}{c}\text { Assay of DRF } \\
(\% \mathrm{w} / \mathrm{w})\end{array}$ & $\begin{array}{c}\text { Mass balance } \\
(\% \mathrm{w} / \mathrm{w})\end{array}$ & Remarks \\
\hline Acid hydrolysis (0.5 N HCl) & $18 \mathrm{~h}$ & 85.3 & 99.8 & Two degradation products (A1 and A2) were observed \\
\hline Base hydrolysis (1 N NaOH) & $24 \mathrm{~h}$ & 99.2 & 99.8 & No degradation was observed \\
\hline Neutral hydrolysis $\left(\mathrm{H}_{2} \mathrm{O}\right)$ & $24 \mathrm{~h}$ & 99.7 & 99.7 & No degradation was observed \\
\hline Oxidation $\left(3 \% \mathrm{H}_{2} \mathrm{O}_{2}\right)$ & 10 days & 77.1 & 99.9 & Two degradation products ( $\mathrm{O} 1$ and $\mathrm{O} 2$ ) were observed \\
\hline Thermal $\left(60^{\circ} \mathrm{C}\right)$ & 10 days & 99.2 & 99.2 & No degradation was observed \\
\hline $\begin{array}{l}\text { Photo solid } \\
\text { solution }\end{array}$ & 10 days & $\begin{array}{l}99.7 \\
99.5\end{array}$ & $\begin{array}{l}99.7 \\
99.5\end{array}$ & No degradation was observed \\
\hline
\end{tabular}

Table 2. System suitability, linearity, sensitivity, precision, and accuracy data.

\begin{tabular}{|c|c|c|c|c|}
\hline Parameter & Imp-1 & Imp-2 & Imp-3 & DRF \\
\hline \multicolumn{5}{|c|}{ System suitability } \\
\hline RT (min) & 4.18 & 20.26 & 17.98 & 9.78 \\
\hline RRT & 0.427 & 2.071 & 1.838 & 1.000 \\
\hline Rs & - & 3.47 & 13.92 & 16.14 \\
\hline$k^{\prime}$ & - & 3.8 & 3.3 & 1.3 \\
\hline As & 1.22 & 0.98 & 1.06 & 1.02 \\
\hline $\mathrm{N}$ & 6935 & 16830 & 11003 & 6272 \\
\hline \multicolumn{5}{|l|}{ Linearity $^{\mathbf{b}}$} \\
\hline Range $(\mu \mathrm{g} / \mathrm{mL})$ & $0.6-3.0$ & $0.6-3.0$ & $0.6-3.0$ & $50-150$ \\
\hline$r^{2}$ & 0.9980 & 0.9992 & 0.9988 & 1.0000 \\
\hline Slope & 170.73 & 204.9 & 178.24 & 18808 \\
\hline Intercept & 292.1 & 194.2 & 339.2 & 27997 \\
\hline \multicolumn{5}{|l|}{ Sensitivity ${ }^{\mathbf{b}}$} \\
\hline $\mathrm{LOD}(\mu \mathrm{g} / \mathrm{mL})$ & 0.07 & 0.20 & 0.20 & 0.15 \\
\hline LOQ $(\mu \mathrm{g} / \mathrm{mL})$ & 0.20 & 0.55 & 0.60 & 0.45 \\
\hline \multicolumn{5}{|c|}{ Precision $(\% \mathrm{RSD})^{\mathrm{a}}$} \\
\hline System & 1.27 & 0.32 & 1.20 & 0.23 \\
\hline Method & 2.56 & 1.41 & 1.77 & 0.79 \\
\hline Intermediate & 2.67 & 3.08 & 0.66 & 0.74 \\
\hline LOQ & 3.21 & 4.82 & 1.75 & - \\
\hline \multicolumn{5}{|c|}{ \% Recovery (accuracy) ${ }^{b}$} \\
\hline $50 \%$ level & 98.8 & 95.6 & 98.9 & 98.7 \\
\hline $100 \%$ level & 100.1 & 99.7 & 98.6 & 100.1 \\
\hline $150 \%$ level & 97.4 & 96.0 & 99.6 & 100.6 \\
\hline
\end{tabular}

RT, retention time; Rs, resolution; $k^{\prime}$, retention factor; As, tailing factor; N, number of theoretical plates; $r^{2}$, correlation coefficient. ${ }^{a}$ Average of six determinations. ${ }^{b}$ Average of three determinations. 


\subsubsection{Accuracy}

At each level, the obtained percentage recovery of DRF assay in the drug substance was ranged from 98.7 100.6, and the percentage recoveries of Imp-1, Imp-2, and Imp-3 were obtained in the range from 95.6 - 100.1. These good recovery results confirm the quantitative ability of the method. The recovery results were given in Table 2.

\subsubsection{Linearity}

The linear calibration plot for the DRF assay method was obtained over the tested calibration range (50 - 150 $\mu \mathrm{g} / \mathrm{mL}$ ) and the correlation coefficient obtained was greater than 0.999 . The linear calibration plots for the related substances were drawn over the calibration ranges LOQ to $3.0 \mu \mathrm{g} / \mathrm{mL}$, and correlation coefficients obtained were greater than 0.996 . The obtained results for both assay and related substances methods showed an excellent correlation between the peak area and analyte concentration revealed the good linearity of the method. Linearity data of DRF and impurities is given in Table 2.

\subsubsection{Robustness}

Careful evaluation of deliberately varied conditions such as flow rate (0.9 and $1.1 \mathrm{~mL} / \mathrm{min}), \mathrm{pH}$ (7.0, and 7.4), and column temperature $\left(22^{\circ} \mathrm{C}\right.$ and $\left.28^{\circ} \mathrm{C}\right)$ showed that the resolution between any two adjacent analytes was greater than 2.0 and tailing factors obtained below 1.5; and variability in the estimation of DRF assay and related substances recovery was within $\pm 1 \%$ and $\pm 9 \%$, respectively indicating the robustness of the method.

\subsubsection{Solution Stability and Mobile Phase Stability}

The \%RSDs of DRF assay and three impurities during the solution and mobile phase stability experiments were within $1 \%$ and $7 \%$ respectively. No significant change observed in the assay of DRF and content of impurities during solution stability and mobile phase stability experiments confirming that sample solutions and mobile phase used during the study were stable up to $48 \mathrm{~h}$.

\section{Conclusion}

A simple and rapid isocratic stability-indicating reversed phase high-performance liquid chromatography method for the determination of DRF and its process-related impurities was developed and validated. Various forced degradations were performed on DRF according to ICH guidelines to study the specificity of the developed method. All of the degradation products and process impurities were well-separated from the drug substance confirming the stability-indicating power of the method. The developed method has been found to be selective, accurate, sensitive and precise, and is applicable for detecting process related substances and possible degradation product which may be present at trace level in bulk drugs.

\section{References}

[1] Hashim, H. and Abrams, P. (2005) Treatment of Overactive Bladder Syndrome and Detrusor over Activity. Reviews in Gynaecological Practice, 5, 243-250. http://dx.doi.org/10.1016/j.rigp.2005.07.003

[2] Haab, F., Stewart, L. and Dwyer, P. (2004) Darifenacin an M3 Selective Receptor Antagonist, Is an Effective and Well-Tolerated Once-Daily Treatment for Overactive Bladder. European Urology, 45, 420-429. http://dx.doi.org/10.1016/j.eururo.2004.01.008

[3] Thomas, S., Paul, S.K., Shandilya, S., Agarwal, A., Saxena, N., Awasthi, A.K., Matta, H., Vir, D. and Mathel, C.S. (2012) Identification and Structural Elucidation of Two Process Impurities and Stress Degradants in Darifenacin Hydrobromide Active Pharmaceutical Ingredient by LC-ESI/MS ${ }^{\mathrm{n}}$. Analyst, 137, 3571-3582. http://dx.doi.org/10.1039/c2an35454c

[4] Murthya, M.V., Krishnaiah, Ch., Srinivas, K., Rao, K.S., Kumar, N.R. and Mukkanti, K. (2013) Development and Validation Of RP-UPLC Method for the Determination of Darifenacin Hydrobromide, Its Related Compounds and Its Degradation Products Using Design of Experiments. Journal of Pharmaceutical and Biomedical Analysis, 72, 40-50. http://dx.doi.org/10.1016/j.jpba.2012.09.013

[5] Meneghini, L.Z., Junqueira, C., Andrade, A.S., Salazar, F.R., Codevilla, C.F., Fröehlich, P.E. and Bergold, A.M. (2011) Chemometric Evaluation of Darifenacin Hydrobromide Using a Stability-Indicating Reversed-Phase LC Method. Journal of Liquid Chromatography \& Related Technologies, 34, 2169-2184. http://dx.doi.org/10.1080/10826076.2011.585486 
[6] Murthy, M.V., Ragavacharyulu, K.S.V., Krishnaiah, C., Srinivas, K., Mukkanti, K. and Kumar, N.R. (2009) A Stereoselective, Stability-Indicating Validated LC-Assay Method for the Separation and Quantification of Darifenacin and Its Enantiomer. Analytical Chemistry: An Indian Journal, 8, 491-493.

[7] Radhakrishnanand, P., Rao, D.V.S. and Himabindu, V. (2008) A Validated LC Method for Determination of the Enantiomeric Purity of Darifenacin in Bulk Drug and Extended Release Tablets. Chromatographia, 68, 1059-1062. http://dx.doi.org/10.1365/s10337-008-0795-Z

[8] Srinivas, K., Reddy, S.R., Reddy, G.M., Dubey, P.K., Chakravarthy, A.K. and Reddy, P.P. (2009) Synthesis and Characterization of Novel and Potential Impurities of Darifenacin, a Potent Muscarinic M3 Receptor Antagonist. Rasayan Journal of Chemistry, 2, 151-155.

[9] Kaye, B., Herron, W.J., Macrae, P.V., Robinson, S., Stopher, D.A., Venn, R.F. and Wild, W. (1996) Rapid, Solid Phase Extraction Technique for the High-Throughput Assay of Darifenacin in Human Plasma. Analytical Chemistry, 68, 16581660. http://dx.doi.org/10.1021/ac9507552

[10] ICH Q2(R1) (2005) International Conference on Harmonization, Validation of Analytical Procedures: Test and Methodology.

[11] ICH Q1A (R2) (2003) International Conference on Harmonization, Stability Testing of New Drug Substance and Products. 
Scientific Research Publishing (SCIRP) is one of the largest Open Access journal publishers. It is currently publishing more than 200 open access, online, peer-reviewed journals covering a wide range of academic disciplines. SCIRP serves the worldwide academic communities and contributes to the progress and application of science with its publication.

Other selected journals from SCIRP are listed as below. Submit your manuscript to us via either submit@scirp.org or Online Submission Portal.
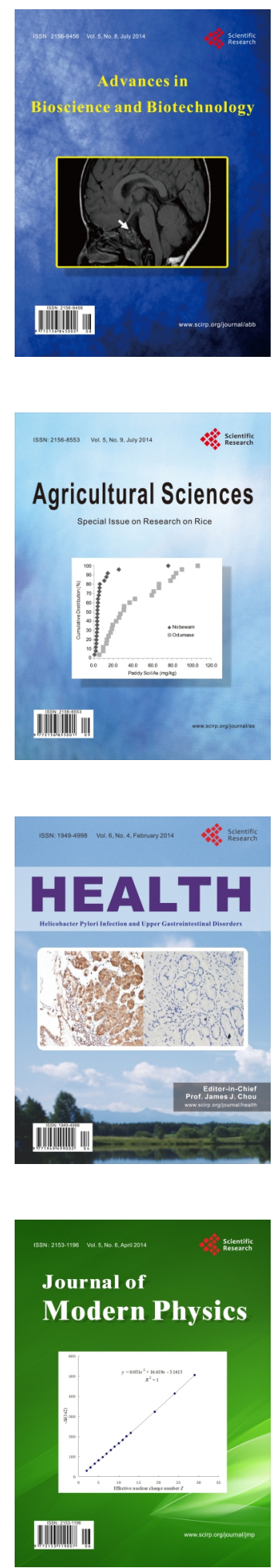
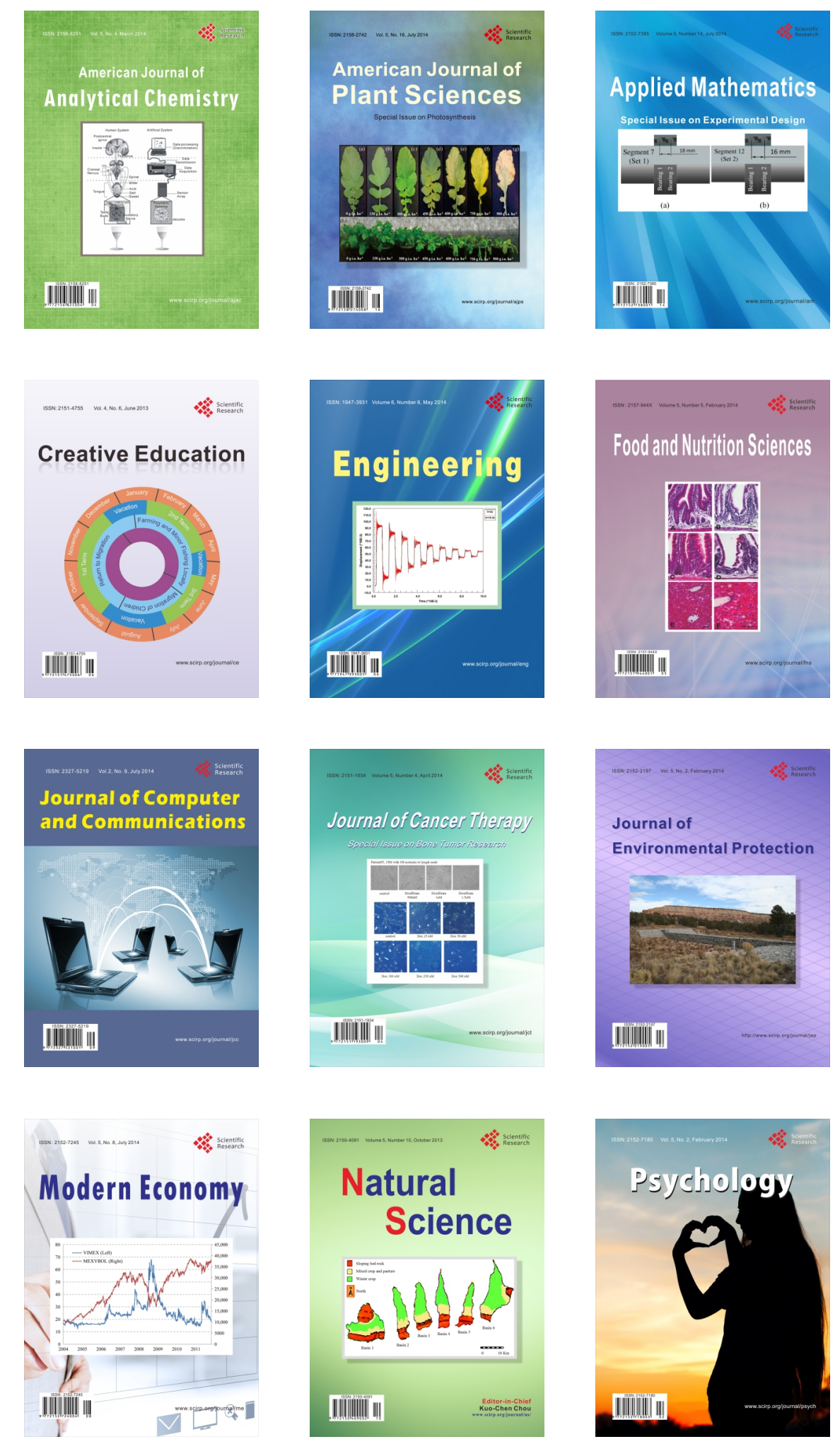